\title{
Use of vedolizumab in a patient with chronic and refractory pouchitis
}

\author{
Eleni Orfanoudaki, Kalliopi Foteinogiannopoulou, loannis E. Koutroubakis \\ University Hospital of Heraklion, Crete, Greece
}

A 22-year-old female presented to our department reporting a new on a series of episodes of pouchitis. Restorative proctocolectomy with ileal pouch-anal anastomosis had become necessary 7 years previously as a result of severe refractory extensive ulcerative colitis. She was first diagnosed with pouchitis 1 year after surgery and had been suffering from recurrent episodes since that time. Initially she was taking antibiotics and prednisolone (for more severe episodes) but since it was a case of chronic refractory disease the treating physicians at that time decided to administer infliximab followed by adalimumab, both of which she discontinued after an early severe allergic reaction and a loss of response attributed to antibody formation, respectively. During the last year she had managed several relapses using antibiotics and prednisolone. Laboratory tests on admission showed white blood cells $12,500 / \mathrm{mm}^{3}$, hemoglobin $10.3 \mathrm{~g} /$ $\mathrm{dL}$, erythrocyte sedimentation rate $58 \mathrm{~mm} / \mathrm{h}$, and C-reactive protein $5.47 \mathrm{mg} / \mathrm{dL}$. A pouchoscopy revealed multiple ulcers, edema, loss of vascular pattern and the presence of fistulas (Fig. 1A). The Pouchitis Disease Activity Index (PDAI) endoscopic subscore was 6 and the histology was compatible with chronic pouchitis. Vedolizumab was subsequently initiated, together with a single course of antibiotics, and the patient experienced improvement in clinical symptoms and laboratory results with no documented relapse since then. A new pouchoscopy at week 33 showed significant improvement (Fig. 1B), with scars and small ulcerations (PDAI endoscopic subscore 2).

This impressive endoscopic improvement highlights the emerging role of vedolizumab as a treatment option for chronic, antibiotic-dependent or refractory pouchitis, validating the existing case series and reports [1-3].

Department of Gastroenterology, University Hospital of Heraklion, Crete, Greece

\section{Conflict of Interest: None}

Correspondence to: Ioannis E. Koutroubakis, MD, PhD, Professor of Medicine, Dept of Gastroenterology, University Hospital of Heraklion, P.O. BOX 1352, 71110 Heraklion, Crete, Greece,

e-mail: koutroui@uoc.gr

Received 5 February 2018; accepted 7 February 2018; published online 3 March 2018

DOI: https://doi.org/10.20524/aog.2018.0243
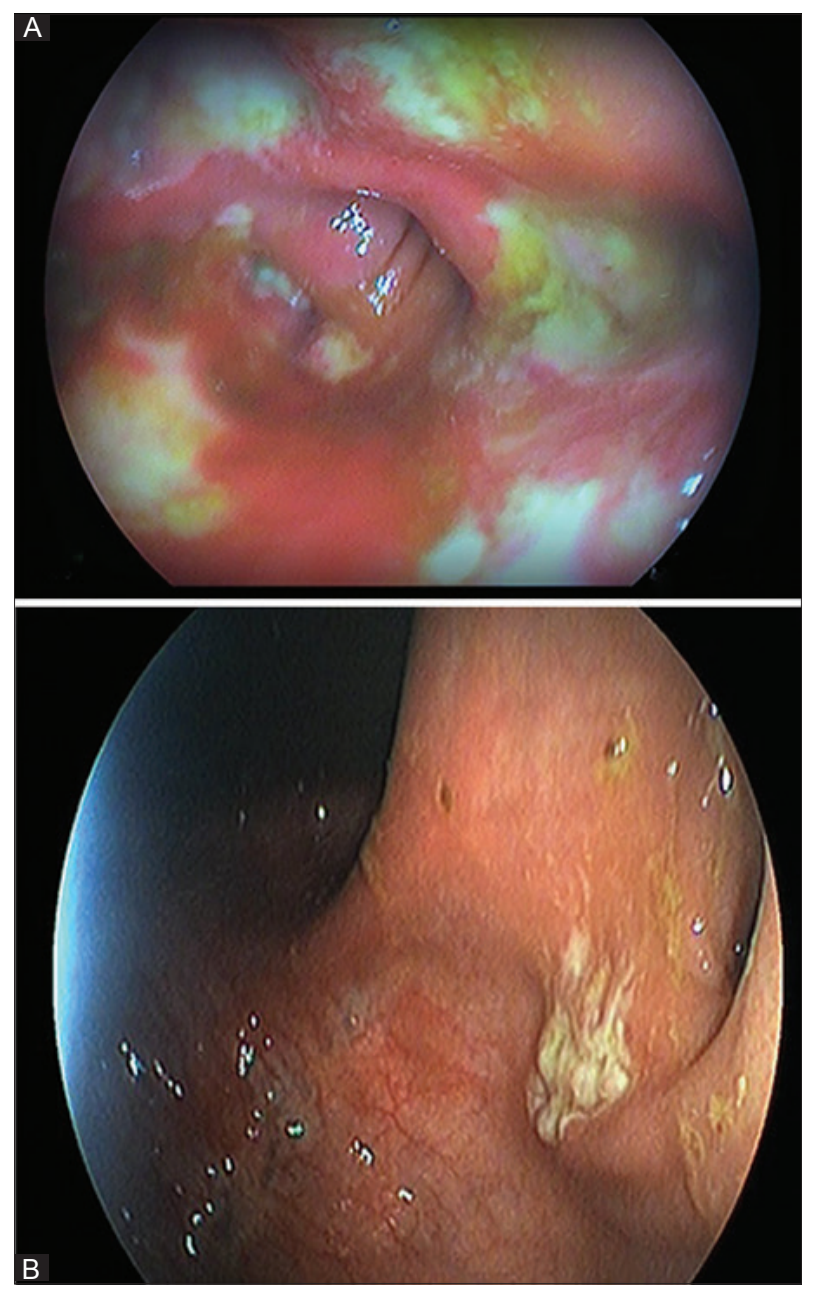

Figure 1 Endoscopic appearance of pouch (A) before vedolizumab treatment and (B) after 33 weeks of treatment with vedolizumab

\section{References}

1. Bär F, Kühbacher T, Dietrich NA, et al; German IBD Study Group. Vedolizumab in the treatment of chronic, antibiotic-dependent or refractory pouchitis. Aliment Pharmacol Ther 2018;47:581-587.

2. Philpott J, Ashburn J, Shen B. Efficacy of vedolizumab in patients with antibiotic and anti-tumor necrosis alpha refractory pouchitis. Inflamm Bowel Dis 2017;23:E5-E6.

3. Coletta M, Paroni M, Caprioli F. Successful treatment with vedolizumab in a patient with chronic refractory pouchitis and primary sclerosing cholangitis. J Crohns Colitis 2017;11:1507-1508. 